\title{
Forecasting inflation and economic growth of Pakistan by using two time series methods
}

\author{
Kishwer Sultana ${ }^{1}$, Adila Rahim², Nighat Moin ${ }^{3}$, Sajida Aman ${ }^{4}$, Saghir Pervaiz Ghauri ${ }^{5}$ \\ ${ }^{1}$ Lecturer, Govt. Degree College, Bufferzone, Karachi, Pakistan \\ ${ }^{2}$ Assistant Professor, Jinnah University for Women, Karachi, Pakistan \\ ${ }^{3}$ Assistant Professor, Jinnah University for Women, Karachi , Pakistan \\ ${ }^{4}$ MS student, Jinnah University for Women, Karachi, Pakistan \\ ${ }^{5}$ Joint Director, Research Department, State Bank of Pakistan

\section{Email address:} \\ kishwer_aftab@yahoo.com (K. Sultana), adila_wali@yahoo.com (A. Rahim), nighat_moin@yahoo.com (N. Moin), \\ sajurani55@gmail.com (S. Aman), saghir.pervaiz@sbp.org.pk (S. P. Ghauri)
}

\section{To cite this article:}

Kishwer Sultana, Adila Rahim, Nighat Moin, Sajida Aman, Saghir Pervaiz Ghauri. Forecasting Inflation and Economic Growth of Pakistan by Using Two Time Series Methods. International Journal of Business and Economics Research. Vol. 2, No. 6, 2013, pp. 174-178. doi: 10.11648/j.ijber.20130206.17

\begin{abstract}
Forecasting of time series is important subject in macroeconomics. We use two time series methods. One of the most simple and basic method for forecasting time series is decomposition. Decomposing the time series means breaking the time series into four components, i.e., trend, cycle, seasonal and irregular. The second method is based on ARIMA model. In this paper we forecast the macroeconomic variables CPI, and LSM for period July 2013 to September 2013, based on decomposition of actual series of these variables and ARIMA model for monthly series from July 2008 to June 2013. We compare the out-of-sample forecast of two methods based on the mean absolute deviation (MAD) \& sum of square of errors (SSE) and decide on which method provides the best forecasting accuracy which policy makers can rely on in forecasting inflation (CPI) and Economic growth (LSM).
\end{abstract}

Keywords: Time Series Decomposition, Trend, Season, Cycles, Irregular and ARIMA Model

\section{Introduction}

Forecasting macroeconomic variables has importance for policy makers, government and monetary authorities. Projection about macro-economic variables provides clear picture of how the state of the economy is likely to perform in the future. It is then crucial for researchers to investigate which models are appropriate and relevant enough to perform an accurate projection of macroeconomic variables, which policy makers, government and monetary authorities can use to predict. This paper intends to forecast two key variables, including inflation and LSM which we are using proxy for economic growth.

Inflation and economic growth are two of the major macroeconomic variables that are closely monitored not only by the government but also the average citizens. They serve as an indication of how the economy is performing and how it is performing in comparison to the countries trading partners. When investors decide on which When investors decide on which country to invest their capital not only do they consider the liquidity of the stock and bond market, interest rate, exchange rate stability and political stability but they also keep a close eye on inflation which gives an idea about the stability of the macroeconomic environment in which investors intent to place their capital and economic growth which signifies the performance of the country's economy. Hence we decided on evaluating the forecasting of inflation and LSM as our key macroeconomic variables.

Of uttermost importance is the fact that forecasting macroeconomic variables provides a clear picture of what the state of the economy will be in future. Having the relevant models to forecast these macroeconomic variables is significant for policy makers and government in allocating resources efficiently. It is evident from the existing literature that not enough papers have considered a decomposition and ARIMA approaches for forecasting for specifically on Pakistani data. Although existing research 
has been conducted in forecasting inflation solely by using ARIMA models. Hence the aim of this paper is to assess the forecasting performance of decomposition method and ARIMA model in forecasting the key macroeconomic variables and thus contributing to the existing literature.

The rest of the paper is structured as follows: next section looks at the existing literature done on this topic; then data and methodology; empirical results and lastly concludes with the overall findings of the paper.

\section{Literature Review}

An extensive number of researches have been conducted not only on forecasting macroeconomic variables but also investigating the performance of alternative model through out-of-sample forecasting. The following models have been considered in forecasting inflation: univariate time series model (ARIMA), Phillips curve, interest rate model and the naïve model. Hafer and Hein (1990) and Alles and Horton (2000) have evaluated the forecasting performance of univariate time series and interest rate models in forecasting inflation. In addition to these models Alles and Horton (2000) also used the error correction model and public survey of inflation forecast. Both papers found that the univariate time series model outperforms or equally performs well as the respective models.

A recent paper by Lee (2012) looked at the predictive performance of the univariate time series model, Phillips curve and the naïve model in forecasting inflation for countries that have adopted inflation targeting. The paper found that the univariate time series model yields superior forecast than the Phillips curve and the naïve model. A wide number of literature [see Hafer and Hein (1990), Ang, Bekaert and Wei (2007)] have also shown that the univariate time-series model (ARIMA) model tends to outperform and/or equally perform the same as the interest rate model or Phillips curve in forecasting inflation in the USA.

Forecasting of macroeconomic variables with nonparametric methods mainly use Artificial Neural Networks (ANNs). Moshiri and Cameron (2000), Kamruzzaman and Sarker (2003), Binner et al. (2005) and Duzgun (2010) compared ANNs to ARIMA models in forecasting inflation. This strand of research finds that the sophisticated ANNs model tends to outperform ARIMA model and performs equally as the ARIMA model in some other cases. However, He et al. (2012) show that ARIMA model are suitable for forecasting inflation in the USA and that ANNs model sometimes cannot improve the forecasting results.

Although there has been an increasing interest in forecasting and assessing macroeconomic variables in South Africa, little has been done on comparing econometric techniques specifically parametric and nonparametric models in order to give an indication on their suitability in making predictions. Woglom (2005) looks at the determinants of inflation forecasts and finds output gap, short term interest rate and import price inflation providing useful information in explaining inflation. On the other hand, Dave et al. (2009) forecast the growth rate of output, inflation and nominal short term interest rate in South Africa using the New-Keynesian Dynamic Stochastic General Equilibrium (NKDSGE) model. The authors compare the NKDSGE model with the classical and Bayesian VAR model and find the former model provides the best forecasting accuracy than the later models.

However, fewer studies on South Africa have considered alternative models of forecasting in South Africa. Gupta and Kabundi (2010) considered five alternative models namely, the small open economy new Keynesian dynamic stochastic general equilibrium (SOENKDSGE) model, small-scale classical and Bayesian vector autoregressive (VAR) model and large-scale dynamic factor models (DFMs) and Bayesian VAR model (BVAR) in predicting per capita growth rate, CPI inflation, money market rate and growth rate of the nominal effective exchange rate. Their forecasting results indicated that the large-scale BVAR model outperformed the remaining models.

To the best of our knowledge, the no paper that uses decomposition and ARIMA models with a case study on Pakistan.

\section{Data and Methodology}

This paper assesses the forecasting performance of decomposition method and ARIMA model, for forecasting inflation (CPI) and economic growth (LSM) in Pakistan. We use log of monthly data, sources from Pakistan Bureau of Statistics from July 2008 to June 2013. The data used for inflation is because new base period 2007-08, starts from July 2008. The out-of-sample forecasting period is July 2013 to September 2013 only 6 observations.

\subsection{Decomposition Method}

There are several approaches to decomposing a time series, all of which aim to isolate each component of the time series as accurately as possible. The basic concept in such separation is empirical and consists of removing first seasonality, then trend, then cyclic and finally irregular component. The functional form of any time series is as follows:

$$
Y_{t}=f\left(S_{t}, T_{t}, C_{t}, I_{t}\right)
$$

Where

$\mathrm{Y}_{\mathrm{t}}=$ Time series value (actual data) at period $\mathrm{t}$,

$\mathrm{S}_{\mathrm{t}}=$ Seasonal component at period $\mathrm{t}$

$\mathrm{T}_{\mathrm{t}}=$ Trend component at period $\mathrm{t}$,

$\mathrm{C}_{\mathrm{t}}=$ Cyclic component at period $\mathrm{t}$

$\mathrm{I}_{\mathrm{t}}=$ irregular component at period $\mathrm{t}$

Further, two functional forms of time series used to relate these four components are generally applied for different series i-e multiplicative and additive models, which are 


$$
\begin{gathered}
\mathrm{Y}_{\mathrm{t}}=\mathrm{S}_{\mathrm{t}} * \mathrm{~T}_{\mathrm{t}} * \mathrm{C}_{\mathrm{t}} * \mathrm{I}_{\mathrm{t}} \quad \text { (Multiplicative rule) } \\
\mathrm{Y}_{\mathrm{t}}=\mathrm{S}_{\mathrm{t}}+\mathrm{T}_{\mathrm{t}}+\mathrm{C}_{\mathrm{t}}+\mathrm{I}_{\mathrm{t}} \text { (Additive rule) }
\end{gathered}
$$

For economic and financial time series multiplicative model is used. We use multiplication model to forecast short term values of CPI and LSM for Pakistan. We can explain the decomposition method as stepby step: first step is we take 12 months moving average (mma) of any time series (Yt) we get TC component (which means by taking $12 \mathrm{mma}$ we eliminate the $\mathrm{S}$ and I components), by taking ratio of $\mathrm{Yt}$ and $12 \mathrm{mma}$ (TC) we get SI component. Now again taking $5 \mathrm{mma}$ of component SI (by taking $5 \mathrm{mma}$ we intend to eliminate I component from the series), so we achieved seasonal component $\mathrm{S}$. By taking ratio of the component SI and S we get component I. The trend component $\mathrm{T}$ can be obtained through simple regression model fitted with time. Then by taking ratio of $12 \mathrm{mma}$ (TC) and trend component $\mathrm{T}$, we obtained component $\mathrm{C}$. In this way we decompose the time series into four components $\mathrm{S}$, $\mathrm{I}, \mathrm{T}$ and $\mathrm{C}$. In order to out-of-sample forecast we take monthly averages of all components except $\mathrm{T}$, where we use forecasted values by using simple regression model.

\subsection{ARIMA Model}

The ARIMA model has been used extensively in time series analysis ever since the publication of Time Series Analysis: Forecasting and Control by Box and Jenkins. The popularity of this model also known as the Box- Jenkins (BJ) methodology is based on the philosophy let the data speak for itself. Stevenson and Mcgarth (2003) considered the model as theoretical, implying that it ignores all other potential theories except the ones that are related to the variable under study.

The generalized ARIMA model with $p, d, q$ has the following specification:

$$
\Delta y_{t}=\alpha+\gamma_{1} \Delta y_{t-1}+\gamma_{2} \Delta y_{t-2}+\cdots \ldots .+\gamma_{p} \Delta y_{t-p}+\varphi_{1} \varepsilon_{t-1}+\varphi_{2} \varepsilon_{t-2} \ldots \ldots \ldots+\varphi_{q} \varepsilon_{t-q}
$$

Where $\alpha$ and $\varepsilon$ denotes the constant error term respectively. The lagged autoregressive (AR) process are symbolized by $p$ and that of a moving average (MA) process are symbolized by $q$ and $d$ being the integrating order of the series.

The formula for MAD \& SSE are as follows: $M A D=$

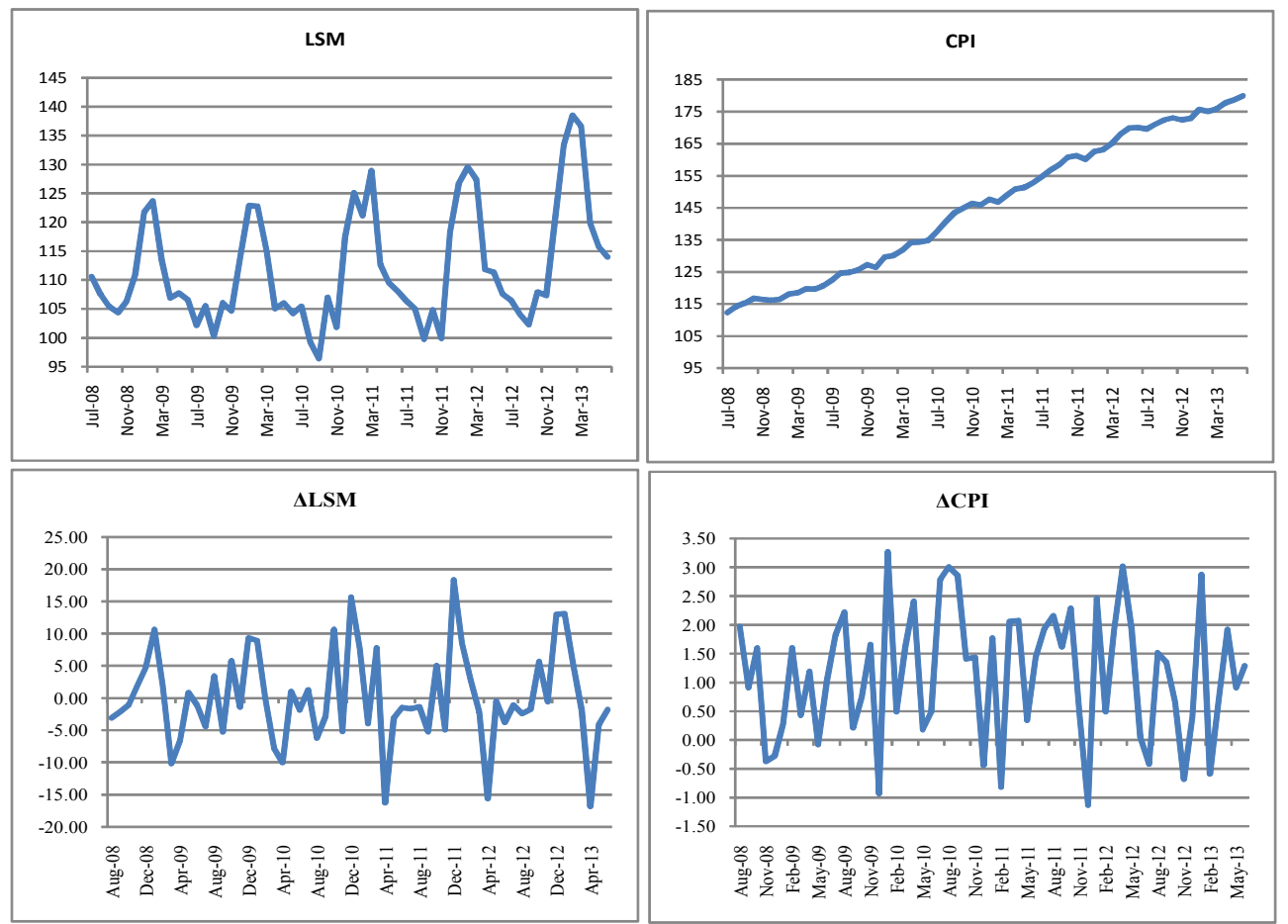

Figure 1. Graph of CPI \& LSM on level and on first Difference

\section{Empirical Result}

Figure 1 clearly explains the time series behavior of both CPI and LSM series. Time series behavior means, both $\frac{1}{n} \sum_{t=1}^{n}\left|y_{t}-f_{t}\right|$ and $M A D=\sum_{t=1}^{n}\left(y_{t}-f_{t}\right)^{2}$, where $\mathrm{y}_{\mathrm{t}}$ are actual values and $f_{t}$ are forecasted values by using both methods. Larger the values of both MAD and SSE means said method predicted best value.

\section{Figure 1. Graph of CPI \& LSM on level and on first Difference}

series shows trend and seasonality specifically for LSM. Both series are non-stationary on levels, but become stationary on first difference. We also apply the formal test for stationatity i.e. Augmented Dickey Fuller (ADF) test on level and first difference. ADF statistic for CPI with 
intercept is -0.10 and for LSM 0.61 whereas critical value is -3.5 at $1 \%$ level of significance, clearly accept the null hypothesis of unit root in both series or non-stationary of series proved. However, when ADF applied to first difference $^{1}$ the null hypothesis rejected, which means series become stationary at first difference or they are integrated of order 1 .

Decomposition method is applied to both CPI and LSM series; Table 1 gives the forecast values for July 2013 to September 2013.

Table 1. Forecasted values by using Decompositions Method

\begin{tabular}{ccc}
\hline & CPI & LSM \\
\hline Jul-13 & 183.09 & 114.05 \\
Aug-13 & 185.42 & 112.45 \\
Sep-13 & 187.37 & 111.45 \\
\hline
\end{tabular}

After thorough investigation of identifying the order of $p$, d, q for ARIMA model, a number of ARIMA models where estimated. For CPI the best fitted model is $\operatorname{ARIMA}(1,1,1)$ and for LSM the model is $\operatorname{ARIMA}(10,1,4)$. The forecasted values for July 2013 to September 2013 by using ARIMA model are as stated in table 2.

Table 2. Forecasted values by using ARIMA Model

\begin{tabular}{ccc}
\hline & CPI & LSM \\
\hline Jul-13 & 183.09 & 114.05 \\
Aug-13 & 185.42 & 112.45 \\
Sep-13 & 187.37 & 111.45 \\
\hline
\end{tabular}

One of the objective of this study is to find the measuring the accuracy of forecasting methods. For this two methods MAD \& SSE are used and Table 3 gives the following results: Which means that ARIMA model give better forecast for both macroeconomic variables when compared by decomposition method. From the table it is clear that method 2 i.e. ARIMA model gives better forecasts for both CPI and LSM from July 2013 to September 2013.

Table 3. Checking Forecasting Accuracy by using two methods

\begin{tabular}{ccc}
\hline \multirow{2}{*}{ Forecasting by Using } & MAD & SSE \\
\cline { 2 - 4 } & \multicolumn{3}{c}{ CPI } \\
\hline Method 1 & 0.99 & 5.10 \\
Method 2 & 2.70 & 23.29 \\
& & LSM \\
Method 1 & 2.24 & 4.60 \\
Method 2 & 19.13 & 100.11 \\
\hline
\end{tabular}

\footnotetext{
${ }^{1}$ ADF statistic for CPI with intercept is -8.03 and for LSM -8.50 whereas
} critical value is -3.5 at $1 \%$ level of significance.

\section{Conclusion}

This study attempts to provide reliable and accurate econometric tool that can be used by monetary authorities and policy makers when making projections about the future values of inflation and LSM being treated as proxy of economic growth in Pakistan. This paper compares forecasting ability of Decomposition method and ARIMA model. Both methods were estimated using monthly data for the sample July 2008 to June 2013 using out-of-sample forecast period of July 2013 to September 2013. We have found that projecting key macroeconomic variables by applying ARIMA on overall series given better result than projecting components of the series and then aggregating to obtain overall forecast. The results seem intuitive as by projecting components and then aggregating also lead to adding up of forecast errors.

\section{References}

[1] Alles L, Horton D.1999. An evaluation of the alternative methods of forecasting Australian inflation. The Australian Economic Review 32 (2) 237-248.

[2] Ang A, Bekaert G \& Wei M. 2007. Do macro variables, asset markets or surveys forecast inflation better? Journal of Monetary Economics 54 1163-1212.

[3] Binner JM., Bissoondeeal RK., Elger T., Gazely AM. \& Mullineux AW. A comparison of linear forecasting models and neural networks: an application to Euro inflation and Euro Divisia. Journal of Applied Economics 37:665-680

[4] Bonga-Bonga L. \& Mwamba M. 2011. The predictability of stock markert returns in South Africa: Parametric VS. Nonparametric methods. South Africa Journal of Economics 79(3) 301-311.

[5] Croushore D.1996. Inflation forecasts: How good are they? Business Review (May) 15-25.

[6] Duzgun R. 2010. Generalized Regression Neural Networks for Inflation Forecasting. International Research Jourmal of Finance and Economics 51 59-70.

[7] Hafter RW. \& Hein SE.1990. Forecasting inflation using interest rate and time-series models: Some international evidence. Journal of Business 63 1-17.

[8] Gupta R, Kabundi A. 2010. Forecasting macroeconomic variables in a small open economy: A comparison between small- and large-scale models. Journal of Forecasting 29 168-185.

[9] He Q., Shen H. \& Tong Z. 2012. Investigation of inflation Forecasting. Applied Mathematics \& Information Science 6 (3): 649-655.

[10] Kamruzzaman J. \& Sarker RA. 2003. Forecasting of currency exchange rates using ANN:A case study. IEEE Int. Conf. Neural Networks \& Signal Processing 14-17

[11] Lee U. 2012. Forecasting inflation for inflation-targeted countries: A comparison of the predictive performance of alternative inflation forecasting models. Journal of Business \& Economic Studies 18 (1) 75-95. 
[12] Liu GD.,Gupta R. \& Schaling E. 2009. A New-Keynesian DSGE for forecasting the South African Economy. Journal of Forecasting 28 387-404.

[13] Ljung GM. \& Box GEP. 1978. On the measure of lack of fit in time series models. Biometrika 65 297-303.

[14] Marcellino M. 2008. A linear benchmark for forecasting GDP growth and inflation? Journal of Forecasting 27: 305340 .

[15] Moshiri S. \& Cameron N. 2000. Neural Networks Versus Econometric models in Forecasting Inflation. Journal of Forecasting 19: 201-217.

[16] Newbold P.1983. ARIMA model building and the timeseries analysis approach to forecasting. Journal of Forecasting 2: 23-35
[17] Ogwang T. 1993. A comparison of the Kernel and the ARIMA estimates of inflationary expectations: Some evidence from Canada. Empirical Economics 18: 281-288.

[18] Stevenson S. \& Mcgarth O. 2003. A comparison of alternative rental forecasting models: empirical tests on the London office market. Journal of Property Research 23 (3) 235-260.

[19] Stock JH. \& Watson MW. 2007. Why has U.S. inflation became harder to forecast? Journal of Money, Credit and Banking 39 (1) 3-33.

[20] Tse RYC. 1997. An application of the ARIMA model to real estate prices in Hong Kong. Journal of property finance 8:281-99.

[21] Woglom G. 2005. Forecasting South African Inflation. South African Journal of Economics 73 (2) 302-320. 